Artigos / Articles 



\section{Migraciones e Inmigraciones en las religiones: la diversidad religiosa en el Medioevo ${ }^{1}$}

Gerardo RODRÍGUEZ•

Resumo: Migraciones e inmigraciones, diversidad religiosa son expresiones que remiten a fluidos y conflictivos contactos culturales. Hombres y mujeres de la Antigüedad y la Edad Media en un juego dialéctico constante de aceptación y rechazo, asimilación y xenofobia; la relación con gentes de costumbres, ideologías, religiones diferentes. Diferentes a los que se teme por muchos motivos, son los "otros", de quienes no se conocen todas las características y que, tal vez, modificarán las peculiaridades del receptor. Esta identidad comporta espacios y límites, espacios y fronteras. Espacios físicos o culturales, reales o anhelados, espacios que nos rechazan o nos aceptan. Espacios limitados, límites múltiples... todos ellos remiten a los contactos culturales y a fronteras.

Palabras-clave: Migraciones; Contactos culturales; Identidad.

Migraciones e inmigraciones, diversidad religiosa son expresiones que remiten a fluidos y conflictivos contactos culturales. Hombres y mujeres de la Antigüedad y la Edad Media en un juego dialéctico constante de aceptación y rechazo, asimilación y xenofobia; la relación con gentes de costumbres, ideologías, religiones diferentes.

Diferentes a los que se teme por muchos motivos, son los "otros", de quienes no se conocen todas las características y que

- Professor Doutor - Departamento de Humanidades - Universidad Nacional Del Sur - 8000FTN - Buenos Aires - Argentina. E-mail: gerodri@sinectis.com.ar 
tal vez, modificarán las peculiaridades del receptor.

Esta identidad comporta espacios y límites, espacios y fronteras. Espacios físicos o culturales, reales o anhelados, espacios que nos rechazan o nos aceptan. Espacios limitados, límites múltiples... todos ellos remiten a los contactos culturales y a fronteras. Que la frontera sea franqueable o infranqueable estará determinado por una serie de condiciones de tipo colectivo o particular. Es decir que la flexibilidad o dureza estarán determinadas por amistad u oposición entre dos entes colectivos o por la aceptación o rechazo de un individuo determinado. Aun rigurosamente custodiada, la frontera implica la relación de dos entidades diferentes ya que comporta la existencia de dos comunidades diversas y el establecimiento de actitudes también diversas ${ }^{2}$.

Identidad y alteridad, homogeneidad y pluralismo son resultado del diálogo cultural y religioso. Un ejemplo de pluriformidad los ofrece el cristianismo de los primeros siglos. Este cristianismo primitivo, plural y multiforme, se cristalizó y en cierto sentido se mitificó ${ }^{3}$ a partir de la visión idealizada plasmada en los Hechos de los Apóstoles, consagrada más tarde por Eusebio de Cesarea en su Historia Eclesiástica.

Pero ¿que ocurrió en esos tiempos primigenios? El movimiento cristiano se diversificó muy pronto y fue diferente en Galilea (como se desprende del documento Q), en Jerusalén (donde adquieren especial importancia las tradiciones referidas a la muerte y resurrección de Jesús) pero la diversidad se hizo mucho mayor cuando, primero los helenistas y después Pablo, abrieron el movimiento a los gentiles, fuera de Palestina. Las relaciones con el judaísmo, las actitudes ante la sociedad y el Imperio, la prolongación posterior de líneas que se pueden comprobar desde muy pronto (trayectorias petrina, paulina, sapiencial, joánica) permiten a muchos autores hablar de los "cristianismos primitivos" $\mathrm{y}$ de los "cristianismos perdidos" ${ }^{5}$. La línea que triunfó, la denominada proto-ortodoxa, lo hace en confrontación fundamentalmente con el judeocristianismo radical (que hubiese hecho imposible la extensión universal) y con el gnosticismo (que hubiese hecho imposible el sentido 
comunitario). La proto-ortodoxia, a pesar de todo, tuvo una gran capacidad inclusiva, hecho que se encuentra reflejado en la enorme pluralidad del Canon del Nuevo Testamento.

¿Por qué hablamos de pluralidad? Porque durante los primeros siglos había cristianos que no creían en un Dios, sino en dos; por un lado, estaba el Dios altísimo y perfecto que Jesús había revelado; por otro, un dios inferior, imperfecto e incluso maligno que era responsable de la creación del mundo material y efímero, y que, a menudo, se identificaba con el Dios veterotestamentario. Estos cristianos eran de la opinión de que, tras la revelación de Jesús, el Antiguo Testamento no tenía ya valor normativo alguno.

Por el contrario, otros cristianos no sólo veían en el Dios del Antiguo Testamento al único Dios, sino que, además, consideraban natural que los seguidores de Jesús se atuvieran a todos los preceptos que este Dios había transmitido a su pueblo, incluso la circuncisión, la observancia del sábado y las reglas sobre alimentos puros e impuros.

También la persona y la misión de Jesús se interpretaban de formas muy diferentes. Los cristianos procedentes de un entorno pagano-helenístico no podían concebir que el cuerpo adoptado por el redentor divino durante su descenso al mundo sublunar tuviera algo que ver con su verdadera identidad. Por ello, tampoco aceptaban que hubiera podido morir en la cruz. Otros, al contrario, pensaban que era blasfemo atribuir a Jesús un origen y poder divinos, pues veían en él al hijo de José, al último profeta que Dios había enviado a su pueblo o al salvador mesiánico de Israel.

Con Ireneo de Lyon se consolida esta vertiente protoortodoxa, que se basa en el Evangelio bajo cuatro formas y el canon de carácter restrictivo. Ireneo esgrimirá su convicción de la "tradición apostólica" que tiene asimilada desde su niñez en el círculo catequético de su querido obispo Policarpo de Esmirna y que ha robustecido en sus desencuentros en la Galia con grupos carismáticos gnósticos. Elaborará de esta manera una peculiar doctrina sobre la sucesión apostólico-episcopal y sobre el Evangelio único bajo cuatro formas. Crece y se establece de este 
modo la base del criterio canónico de carácter restricto o por supresión de escritos, antes que el abarcativo y amplio que fue su primera forma cristiana. A partir de esta mentalidad exitosa se explican igualmente los acuerdos programáticos establecidos después del Edicto de Milán o de tolerancia religiosa promulgado en el 312 por el Emperador Constantino, a lo largo del siglo IV con los obispos de Roma, Capadocia, Alejandría, Galia e Hispania, el posterior y maduro Decreto Gelasiano (496), etc. La legislación procatólica de los Emperadores Teodosio y Justiniano debe entenderse dentro de la misma concepción ${ }^{6}$.

Esta lógica es la que esgrimen Leandro e Isidoro de Sevilla, por ejemplo, lógica que afirma que cuando Recaredo se convierte oficialmente al catolicismo y con él la corte visigoda y apoya la celebración de los Concilios de Toledo que llegan a su auge con el IV (633), en las decisiones reales estaban gravitando fuertemente las enseñanzas de los hermanos béticos Leandro e Isidoro de Sevilla, que habían elaborado la teología política de que la concepción genuina del imperio se había trasvasado de los restos del imperio romano al visigodo, porque el primero alcanzó la universalidad que otorga el mando o poder material pero no la que está fundada en la catolicidad del cristianismo, que sólo correspondía a un monarca cristiano.

Religión y política unidas estrechamente, en función de la conformación de identidades "nacionales", que son resultado de elaboraciones ideológicas y textuales. De allí la posibilidad de utilizar la noción "invención de tradiciones" que, en un sentido amplio, permite dar cabida tanto a las tradiciones realmente inventadas, construidas $\mathrm{y}$ formalmente instituidas, como aquéllas que emergen histórica y culturalmente, en un período que es difícil precisar pero que se consolidan con rapidez ${ }^{7}$.

Ambas formas de tradiciones buscan inculcar determinados valores o normas de comportamiento mediante ciertas reglas, mayormente de naturaleza simbólica o ritual, a la vez que fijar una interpretación del pasado, que llega a conformar la memoria histórica y cultural de determinada sociedad. 
Los elementos que subyacen a esta invención son de muy variado tipo y remiten tanto a tradiciones orales como a personajes históricos o de leyendas, a valores éticos como a cuestiones religiosas.

Un ejemplo de lo dicho lo podemos encontrar en el panegírico In Honorem Hludowici Pii de Ermoldo Nigello, en particular las relaciones establecidas entre el mundo carolingio y la tradición cristiana, puestas de manifiesto claramente en la advocación a María realizada en el Libro IV, versos 2529-2627.

Ermoldo, historiador de amplia cultura, probablemente clérigo, "transmite un mensaje espiritual", que "respira la ética del período en el que nace" ${ }^{\prime \prime}$. En su poema, retoma conscientemente la tradición, tanto de raigambre religiosa como secular, para elaborar un texto destinado a Luis el Piadoso, que escribe invocando a Cristo, pero poniendo en primer plano tanto su figura como su práctica escrituraria ${ }^{10}$.

En Ermoldo "el Negro" se conjugan tradición e innovación. En particular, esta innovación se plasma en la presentación de la Virgen, presentación que se relaciona en el proceso de construcción del personaje marial, que sufre, en Occidente, una aceleración entre los siglos IX y X, tanto a nivel litúrgico como devocional. Se asiste, entonces, a una individualización de la figura de María y a la revalorización de su papel en la creación de la societas christiana ${ }^{11}$.

Durante el período carolingio, el clero logra un control progresivo del culto, que ve en María a una mujer fuerte, equivalente a una figura de gloria militar, que posibilita una constante interacción entre el mundo temporal y el mundo espiritual. María y la Iglesia, en los textos de los siglos IX a XI, son inscriptas en el mismo campo metafórico: Corpus Christi, Navis, Sponsa y Mater.

Esta tradición refuerza las valencias de los binomios Imperio-Papado, Reino-Iglesia, Carolingios-Cristiandad a partir de una imagen de María que se asocia a las virtudes y valores asumidos y sostenidos por los monarcas carolingios, particularmente Carlomagno y Luis el Piadoso. Esta asociación enfatiza la importancia de la Virgen, que en el año 800 merece la 
composición del primer himno propiamente marial: Ave Maria stellis.

Los versos seleccionados de la obra de Ermoldo permiten observar cómo la historiografía carolingia hace suyas cuestiones esenciales del pensamiento cristiano, para plasmarlas en un discurso histórico que difunde una ideología imperial de raíz católica. Daniel Russo afirma que, en este período, se leyó a María desde dicha ideología, que la puso al servicio de la representación de cierta idea de soberanía. Es la Virgo militans, que aparece asociada a la Regina gloriosa.

Éric Palazzo y Peter Godman subrayan la importancia de nuestro autor en la construcción de una devoción marial que acentúa su papel de intercesora y su carácter de suplicante por el género humano ante su Hijo. Y esta intercesión toma cuerpo en los milagros mariales, que harán eclosión recién en el siglo XI, pero que encuentran en Alcuino, Rábano Mauro, Hicmar de Reims y Ermoldo a sus primeros cultores.

In Honorem narra dos milagros acontecidos en la Iglesia de Estrasburgo ${ }^{12}$, dedicada a María, tanto para su culto terrestre como para su celebración y honor (v.2529-33) ${ }^{13}$.

En el texto la presentación del recinto resulta poderosa en cuanto a imaginería religiosa se refiere: los habitantes del cielo y un coro de ángeles frecuentan el templo (v.2534-35), dado que la Virgen se encuentra favorecida por la Gracia divina (v.2539), tal como se afirma en la tradición neotestamentaria y bizantina, en particular en el himno litúrgico de la antigua iglesia griega Akáthistos.

Los milagros mencionados son los siguientes: Primer milagro (v. 2544-63): Theutram, guarda de la Iglesia desde tiempos recientes, vigila tanto de noche como de día el santuario. Le cuenta a Ermoldo que una noche, antes de retirarse a dormir luego del canto de los salmos y de los himnos, la Iglesia se iluminó con una gran claridad, como si fuera un bello día soleado, tras lo cual apareció un ave: su pico era de oro, sus garras aparecían como gemas preciosas, sus alas eran de color azul. El guarda se levantó al ver la radiante luminosidad en el santuario. Las alas del ave, semejante a un águila, envolvían 
el altar. No había en la tierra nada parecido a aquella ave. El águila, en el momento en que retumbó el tercer canto del gallo llamando a los religiosos a los oficios ${ }^{14}$, voló y se escapó. Se dirigió al cielo y con ella la luminosidad, demostración de que era un ave divina.

Segundo milagro (v.2564-2614). Nuevamente Theutram cuenta la visión que tuvo: los clérigos se encontraban cantando los salmos, delante del altar de la Iglesia y se disponían a pasar la noche suplicando a Dios. Entonces un violento temporal habla de truenos y viento violentos- se abatió dentro de la Iglesia. Llenos de terror, se arrojaron al suelo, se prosternaron en la nave y, cuando esperaban que pasara lo peor, todo se calmó repentinamente. Theutram miró al cielo para conocer la razón de toda esa conmoción y observó cómo la bóveda de la habitación sagrada se abría, majestuosamente, tres hombres, descendieron del cielo inundando todo de luminosidad, vestidos de blanco, blanco su cuerpo y la cabeza coronada de blanco -de un blanco semejante a la leche y la nieve- ${ }^{15}$. El del medio, el de más edad, avanzó religiosamente, apoyándose sobre los otros dos. Una vez puestos los pies sobre el suelo, avanzaron hacia el altar de la Virgen y le dirigieron una plegaria. Luego visitaron los otros altares del templo, adorándolos, como el resto de los mortales: sus bocas articularon las palabras y pronunciaron las plegarias rituales. En el costado derecho del coro se encontraba el altar de san Pablo; en el izquierdo, el dedicado a san Pedro, representado como doctor, custodio de la entrada al cielo; entre ambos, los dos rayos poderosos de la Madre de Dios. San Miguel y la cruz ocupaban el centro; en la otra extremidad se honraba el crisma de Juan Bautista. Los tres visitantes, manteniéndose en la tierra, dirigieron sus plegarias a los santos, aquéllas que se dedican habitualmente a las almas que se elevan hacia Dios.

El sacerdote, testigo de estas intervenciones, se pregunta por el significado que puede atribuirse a esta orar delante de los cuerpos de los santos; también se interroga por qué en la tradición cristiana muchas plegarias se dirigen a Dios por medio de sus servidores. Pedro no es Dios pero le rezamos a él, como si lo fuera. Esto hicieron los tres hombres en el Templo de María y 
cuando terminaron sus devociones, regresaron al cielo. Tras esto, el sacerdote se arrodilló en el suelo, dirigiéndose a los demás, recriminándoles que estaban adormecidos cuando debieron haber visto todo lo que el observó y cuenta, que entiende fue una revelación.

En estos relatos Ermoldo reconoce la ejemplaridad de María $^{16}$, puesto que grande es su autoridad en el cielo, grande es su presencia en la tierra, es la Madre del Padre del mundo. De allí que le pida se acuerde de los hombres, dado que su sola presencia es remedio contra los males del mundo terrenal, en especial del exilio (v.2624-25).

La introducción de la figura del exiliado nos remite al contexto político en que estos versos se encuentran inmersos, más allá de las referencias a otros personajes y situaciones históricas como el venerable Bonifacio y su labor entre los frisones, difundiendo el cristianismo (v.2614-17). Pero, dejando de lado la historicidad de la obra, ¿cómo pueden interpretarse estos relatos milagrosos?

En primer lugar, recojo las referencias a la nocturnidad. $\mathrm{Me}$ interesa destacar las posibles relaciones existentes entre el desarrollo de los milagros y la noche/oscuridad como momento propicio y propiciatorio para la manifestación de la acción divina. Cabría preguntarse, entonces ¿cuál es su función simbólica dentro de la retórica discursiva cristiana? Como otros muchos tópicos simbólicos, la noche se presenta de manera ambivalente, ya que a la vez es la vida y la muerte, las ensoñaciones y los engaños.

$\mathrm{Su}$ aspecto positivo simboliza el tiempo de las gestaciones, que estallaran a plena luz del día como manifestaciones de vida. He aquí puesta de manifiesto la importancia de la oscuridad en la obra divina. Entonces, pues, la noche nos remite a este tiempo primigenio, primordial, a partir del cual Dios procede a la creación. Y, en sentido figurado, a una recreación constante y permanente de su obra por medio de su presencia en la vida cotidiana.

Los relatos refieren que la noche se ve interrumpida por una gran luminosidad y claridad que, en todos los casos, se 
relaciona con lo milagroso, en su aspecto animal (águila) o en su aspecto humano (los tres hombres). Sin duda, ambos remiten al hombre como eje de la presencia divina y a la necesidad permanente de protección, tal como invoca posteriormente el mismo autor ${ }^{17}$.

En segundo lugar, interpreto tales relatos como presencia de la providencia y la revelación. En el primer milagro, el águila puede leerse como imagen de la providencia divina sobre el pueblo de Israel ${ }^{18}$, en tanto que la visión/revelación del segundo milagro puede analizarse como revelación de alguna verdad concerniente al misterio de la redención por Cristo ${ }^{19}$.

En tercer lugar, considero que ambos textos resultan de interés e importancia para precisar la evolución cultual en época carolingia. Al respecto haré cuatro breves referencias.

La primera, relaciona las alas extendidas y el vuelo del águila del primer milagro, con las Virtudes, especialmente las de la Esperanza, la Caridad, la Verdad, la Pobreza evangélica y la Penitencia ${ }^{20}$. Estas Virtudes, particularmente las tres primeras, comienzan a plantearse en relación con María a partir del siglo VIII y, en Ermoldo, encuentran plasmación en la inclusión de la figura del exiliado.

La segunda, interpreta al número tres del segundo texto, desde una perspectiva alegórica. En tal sentido, remite a los crucificados del Gólgota y, por ende, a la Pasión. En un sentido simbólico de mayor alcance es expresión de la Trinidad y del proceso completo de la realidad (comienzo, desarrollo y fin).

En tercer lugar, la referencia quizás más importante en lo relativo al culto mariano, la pregunta retórica del porqué las plegarias a los santos, en particular a Pedro. Esta cuestión, que entre los siglos III y VIII dio origen a la pasión por las reliquias y a la importancia de los santos en la intercesión divina, comienza a ser cuestionada y la figura de María aparece como la otra cara del fenómeno. La Virgen es, desde mediados del siglo VIII y según una antigua tradición greco-bizantina, mediador natural y canal de todas las gracias ${ }^{21}$.

En cuarto y último lugar, la estructura física de la Iglesia, que remite, desde la propia construcción, a la imagen de Virgen 
reina elaborada por los carolingios ${ }^{22}$. De allí que la imagen de María se encuentre en el centro de la Iglesia y que, en el segundo milagro, los rayos de luz provengan de dicho lugar.

En síntesis, In Honorem nos permite analizar como se escribe y se lee la tradición en la alta Edad Media, a partir del caso del reino franco en lo novena centuria, a partir de la advocación realizada a la Virgen María.

En el siglo XIII, Joinville -el cronista, biógrafo y amigo del rey san Luis- menciona la presencia de un francés en Egipto ${ }^{23}$. El monarca -junto a Joinville- estaba esperando que sus gentes pagaran el rescate que permitiría libertar de manos de los musulmanes a su hermano, el conde de Poitiers. En esa espera, ven llegar a un hombre bello y elegantemente vestido, traía presentes. Los ofreció hablando en francés. El rey preguntó entonces dónde había aprendido la lengua. El recién llegado contestó que había sido cristiano; ante ello, el rey, irritado, lo rechazó y lo incitó a irse. Pero Joinville, en un aparte, quiso conocer su posición. El hombre dijo entonces que había nacido en Provins, que había llegado a Egipto con el rey Juan y allí se había casado y hecho fortuna, se había convertido en un gran señor. Joinville entonces le recordó que moriría condenado. El visitante aceptó tal hecho pues consideraba que ninguna religión era mejor que la cristiana. Pero dijo que si regresaba a su patria sólo encontraría pobreza y reproches por su condición de renegado.

En este caso, el individuo ha traspasado una frontera y ya no puede volver atrás, el precio que ha de pagar para hacerlo resulta demasiado caro, la frontera se ha tornado infranqueable. Esto le ocurrirá, entre los siglos XIV y XVI, a los renegados de Alá, es decir, a muchos de aquellos que por salvar su vida reniegan de su fe y son luego juzgados por la Inquisición.

Situaciones similares a la de la anécdota recogida por Joinville. Experiencias individuales en que se añoran o se resignan orígenes, confesión, el lugar natal...

En ocasiones la antigua identidad se diluía. Luego de la constitución de los principados "francos" en Tierra Santa, 
muchos cristianos se han aposentado en el cercano Oriente $\mathrm{Y}$ dice el cronista de la primera cruzada Foucher de Chartres:

Considerad y reflexionad en vuestro espíritu de qué manera, en nuestro tiempo, Dios ha transformado el Occidente en Oriente. Nosotros que hemos sido occidentales, nos hemos convertido en orientales. Quien era romano o franco se ha transformado en galileo o habitante de Palestina, quien habitaba Reims o Chartres se ve ciudadano de Tiro o de Antioquía. Hemos ya olvidado los lugares de nuestro nacimiento, ya son desconocidos para bastantes de nosotros o, por lo menos, no sentimos ya hablar de ellos. Algunos de entre nosotros poseen en aquellas regiones casas y servidores que les pertenecen como por derecho hereditario, otro se ha casado con una mujer que no es, en absoluto su compatriota, una siria o una armenia o inclusive una sarracena que ha recibido la gracia del bautismo. [....] Los idiomas más diversos son ahora comunes a una y otra nación y la confianza acerca a las razas más alejadas. En efecto, ha sido escrito: 'el león y el buey comen en el mismo comedero'. Aquél que era extranjero ahora es indígena, el peregrino se ha convertido en habitante, día a día nuestros parientes llegan a reunirse con nosotros aquí, abandonando los bienes que poseen en Occidente. Aquellos que eran pobres en sus países, aquí Dios los ha enriquecido [....] ¿Por qué debería retornar a Occidente aquél que encuentra un Oriente tan favorable?

Hay cercanía y alianzas -a veces circunstanciales- que permitieron un conocimiento de ciertos aspectos del "otro", conocimiento tal vez incompleto y limitado a las facetas de la relación en juego. En general, la visión del Oriente, de ordinario considerado como "otro" y "extraño" depende, en gran medida, de las circunstancias políticas que envuelven ambas entidades. Decimos visión y no conocimiento porque en muchas situaciones el conocimiento se imponía de manera ineludible por cercanía, por ejemplo en el caso de Al-Andalus. En esa relación se plantea no sólo cercanía sino una convivencia. Y, sin embargo, en testimonios literarios y en crónicas, en imágenes, el retrato que se hace del "otro" no sólo es frecuentemente negativo desde el punto de vista moral y de costumbres sino también como 
representación física, una deformación que no corresponde a la inmediata realidad conocida. Podemos hablar pues de construcción intelectual y de representaciones imaginadas. Estos elementos se encuentran en testimonios bizantinos, musulmanes y cristianos. Sin duda, la incomprensión de lenguas fue determinante pero también la ignorancia de costumbres y usos según hemos visto. La prolongada permanencia en lugar extraño a veces borra una de las formas de identidad que es la lengua. Varthema dice que en Calcuta conoce a dos milaneses, maestros artilleros que enseñaban sus artes a los naturales. Pero Varthema encuentra dificultad para expresarse:

Verdaderamente yo no podía hablar cristiano, me parecía tener la lengua hinchada e incapaz de pronunciar palabra porque yo, durante cuatro años no había hablado con cristianos.

Por todo lo expuesto, coincido con Floreal Forni quien señala que "el sustrato religioso de la cultura es uno de los elementos claves para comprender el conjunto de valores, símbolos, legitimaciones e interpretaciones del mundo que la orientan" ${ }^{24}$.

Veamos ahora esta noción aplicada a Los Milagros de Guadalupe $^{25}$, Sobre la conquista de Granada ${ }^{26}$ y Tratado de la redención de cautivo ${ }^{27}$ a partir de un análisis que tenga en cuenta, principalmente, su estructura y funciones discursivas.

Parto de la hipótesis siguiente: los códices guadalupanos, el panegírico de Verino y el tratado de Gracián evidencian la elaboración doctrinal de la creencia cristiana de los siglos XV y XVI en general y de la devoción mariana en particular. En tal sentido entiendo que monjes jerónimos o carmelitas o bien los escritores estrechamente vinculados con los círculos de poder eclesial al redactar sus textos, implementaron diversas estrategias y prácticas discursivas tendientes a expurgar de los relatos toda connotación heterodoxa, ajena a la ortodoxia cristiana de la época.

Estas diversas prácticas y estrategias eran conocidas en medios monásticos, habituados a buscar nuevas y mejores 
interpretaciones del material documental mediante la utilización y manipulación de textos bíblicos -tanto canónicos como apócrifos-, dado que los grados de saberes desarrollados equivalían a los grados de poderes ejercidos.

En otras palabras, los monjes jerónimos anónimos del Real Monasterio de Guadalupe, Ugolino Verino y Jerónimo Gracián pusieron sus conocimientos al servicio de la construcción de un habitus catholicus, es decir, de una manera genuinamente cristiana de ver y comprender el mundo, basada en la devoción mariana de los siglos XV y XVI. Hacia fines de la década del sesenta y principios de la del setenta, Pierre Bourdieu definía al habitus como "disposición cultivada", que "permite a cada agente engendrar, a partir de unos pocos principios implícitos, todas las conductas que se ajustan a las reglas de la lógica del desafío y de la réplica y a ellas únicamente" 28 .

El concepto de habitus elaborado por P. Bourdieu remite a ambas cuestiones, dado que se relacionan tanto con la acción como con la percepción del mundo. El habitus remite a los hábitos colectivos, forjados cultural e históricamente; constituye un sistema de estructuras estructurantes. En lo colectivo, determina formas de ver el mundo que se materializan en el plano individual, corporal. Así, por ejemplo, toda la discusión "nosotros" - "los otros" en cuanto a verdades de fe y razones concretas de prácticas religiosas, encuentra en la circuncisión una razón de control social, dado que no se puede "escapar" de ella. Jerónimo Gracián lo expone claramente: "He visto traer a Túnez y a Bicerta abundancia de muchachos franceses, y porque no pueden ser esclavos por la liga que hay entre los turcos y Francia, antes que el Cónsul de su nación los pida, los circuncidan por fuerza. A uno de éstos di una patente para la Inquisición con que se huyó y vino a Cagliari"29.

Los discursos generan o inhiben prácticas sociales, reproducen la dominación y desalientan el ejercicio de la crítica, derrumban las viejas legitimidades y justifican la rebelión, contribuyen a otorgar sentido al mundo que habitamos, fundamentan la inmovilidad y generan el cambio. Es por ello que las prácticas discursivas son variadas y expresan tanto 
ideologías como mentalidades, muchas veces en pugna, contradictorias. Prácticas y representaciones se entrelazan y dinamizan mutuamente.

Silviano Santiago subraya la íntima y profunda relación entre código lingüístico y código religioso ${ }^{30}$. El control lingüístico se impone como medio o mecanismo para evitar el pluralismo religioso, lo cual significa también imponer un determinado orden o poder, de allí que hable de "imperialismo cultural". Sin embargo, esta dominación genera resistencias, agresiones, rebeliones, transgresiones que se expresan en las prácticas religiosas vividas.

Esta imposición supone dos esferas bien determinadas o, en la terminología de P. Bourdieu, una religión oficial impuesta por los dominantes y una religiosidad popular que expresa a los dominados. En el contexto de este estudio, entiendo que la religión popular es, conjuntamente, complemento dialéctico culto-popular a la vez que vivencia religiosa.

El estudio del discurso adquiere una importancia fundamental para la comprensión el cuerpo textual seleccionado. Los conceptos allí recogidos expresan discursos que remiten -a la vez que modelan- a prácticas sociales y sistemas ideológicos hegemónicos. Incluso, siguiendo a Manuel Ambrosio Sánchez podría hablarse de "discurso religioso" aplicado a textos diversos tales como sermones, sínodos, catecismos, manuales de confesión o tratados religiosos de distinta índole ${ }^{31}$. Esta consideración se deriva de la concepción de la iglesia como espacio físico y la Iglesia como espacio o complejo ideológico que busca -a través de diferentes entramados textuales y manifestaciones discursivas- influir en el sentir de la gente y conseguir la unidad a toda costa, especialmente entre los siglos XIII y XV e incluso más allá del 1500.

En este mismo sentido se manifestó Grado Merlo al estudiar la Storia di fra Michele Minorita, una obra anónima de fines del siglo XIV, que permite comprender las prácticas inquisitoriales no solamente como instrumentos de represión sino, fundamentalmente, como un modo de comunicar e imponer un mensaje religioso ortodoxo. Gracias a un ritualismo de hechos 
y gestos, de símbolos, de palabras y de sentencias, la inquisición medieval logra eficazmente su doble función: suscitar adhesión a través de la represión ${ }^{32}$.

En esta religiosidad popular es esencial el sincretismo entre discurso religioso oficial, tradiciones populares y folklore. De allí que tomo y aplico la definición dada por Francisco Fernández Conde, para quien la religiosidad popular es "un sistema global para comprender y explicar la realidad, en el que el subsistema dominante sería la religiosidad propia de la cosmovisión cristiana, recibida por el pueblo a partir de la enseñanza multisecular y tradicional de la iglesia institucionalizada, y con él convivirían también, con su influencia más o menos determinante y en muchas ocasiones vacías de contenidos existenciales, otras realidades religiosas que podrían ser consideradas como subsistemas. Entre el sistema general [...] y los restantes subsistemas funcionaron y funcionan todavía las normales correlaciones de estructura dialéctica, formas dinámicas de retroalimentación positiva o negativa, que hacen del conjunto o de la totalidad religiosa de los pueblos un sistema multiforme, bien entramado, dinámico y diacrónico, con cambios y variables, siempre de larguísima duración, pero en cualquier caso verdaderamente históricos y con evidentes implicaciones sociales" ${ }^{33}$.

En este contexto aplico las nociones desarrolladas por $P$. Bourdieu -en particular las de campo y habitus- al abordaje e interpretación de los textos seleccionados. Parto de su interpretación de la religión como lenguaje, en tanto instrumento de comunicación como de conocimiento. Así entendida, la religión es un medio simbólico estructurado (ordenamiento propio como campo) y estructurante (capacidad para estructurar ortodoxia, religiosidad y consenso) ${ }^{34}$. O, palabras de Pedro Cátedra, "un convento, dentro de una obediencia religiosa, funciona como una sociedad vinculada, si, por las creencias, pero sobre todo ordenada sobre la base de los textos, como las reglas, las consuetudines, que a su vez se refieren al cumplimiento de normas basadas en la guía de otros textos de muy diversa índole, litúrgica o espiritual, por ejemplo. Es, así, 
una comunidad normativa porque funciona como una subcultura con referentes propios y que comporta un alto grado de ritualidad. Es también una comunidad textual, en sentido amplio, porque tiene al intérprete como figura necesaria reglamentada en prácticamente todas sus manifestaciones, o la erige aleatoriamente según un ritmo marcado por la norma"35.

Esta interpretación otorga sentido a la existencia de un corpus documental como el conservado en Guadalupe, dado que refleja la acción racional, sistemática y burocrática de los jerónimos por producir, reproducir y difundir determinados bienes religiosos o bien las prácticas escriturarias de Verino y, en particular, de Jerónimo Gracián de la Madre de Dios, quien representaría la acción racional, sistemática y burocrática de los carmelitas. Es decir, el corpus de milagros, los textos de Verino y Gracián así como crónicas e historias referidas a la Virgen de Guadalupe, a las órdenes religiosas, a los fenómenos entrelazados de cautiverio - redención, cautivos - renegados pueden ser considerados textos históricos que narrativizan, dado que presentan los hechos como si hablaran por sí mismos, al construir la realidad histórica como un relato.

Esta acción tiene por finalidad el logro de consensos, la construcción de un mundo basado en una determinada lógica de inclusión/exclusión social. De allí la relación entre ideología religiosa y división de clases, entendida tanto como legitimación de un orden social como una domesticación de los dominados.

Aplicadas estas consideraciones a los relatos de liberación milagrosa de cautivos es posible señalar que:

- La legitimación del orden social se vincula tanto con la acción de los monjes por controlar un determinado culto como con la imposición de una determinada ideología que transforma al cautivo en factor determinante $y$ excluyente del conflicto religioso con el islam.

- La domesticación de los dominados refleja la asimilación de determinadas reglas y prácticas consideradas esenciales y ortodoxas, que se transmiten por medio de largas disquisiciones puestas en boca de los personajes de los relatos. Así, algunos 
afirman que no han sido liberados por los pecados cometidos en tanto que otros manifiestan sus creencias por medio del rezo del padrenuestro o bien por los ayunos respetados, a pesar del hambre que implica el cautiverio.

Por ello, es factible considerar a los jerónimos, a los carmelitas y, aunque con algunos matices, a Ugolino Verino como agentes especiales del campo religioso, en tanto productores de prácticas y discursos específicos. He aquí una de las funciones principales de los sacerdotes -en este caso, de los monjes- de acuerdo a la concepción $\mathrm{P}$. Bourdieu -que remite a la elaboración realizada por Max Weber-. El relato milagroso constituye, pues, una fuente susceptible de ser interrogada, siempre que se le reconozca su singularidad. Esta singularidad implica reconocer que estamos en presencia de una elaboración doctrinal, que al plasmar por escrito un acontecimiento lo está creando y fijando en la memoria colectiva, convirtiendo en recuerdo algo que no es experimentado por la mayoría de quienes participan de ese recuerdo, es decir, de ese colectivo religioso.

Es fundamental, entonces, el análisis de las prácticas discursivas, de las relaciones planteadas entre tradición oral y narración escrita, de las tensiones existentes entre religiosidad popular y ortodoxia doctrinal. El acto de narrar es lo que da sentido a este conjunto y evidencia la construcción social y discursiva de esta creencia.

Se conforma así un campo religioso autónomo, en el cual los sacerdotes y monjes monopolizan el creer y el cómo creer dentro de una comunidad religiosa conformada tanto por los creyentes como por la cofradía sacerdotal. La función específica de este campo es satisfacer el interés religioso, lo cual constituye una demanda propiamente ideológica, de allí el sentido unitario del mensaje, entendido como la justificación de la existencia de una posición determinada.

Sin duda, este monopolio -y la consecuente manipulación de lo sagrado- se refleja con claridad en la labor desarrollada dentro del monasterio, dado que el accionar de los monjes 
posibilitó tanto la construcción de una determinada experiencia como su consagración y legitimación. De esta manera se produce lo que $\mathrm{P}$. Bourdieu denomina absolutización de lo relativo y legitimación de lo arbitrario.

En esta perspectiva, la religión tiene tres funciones básicas -ideológica, práctica y política- que se relacionan en el dominio de una clase determinada, por medio de la manipulación simbólica de las aspiraciones y la reproducción de las estructuras vigentes. A modo de ejemplo, los elementos que definen la ortodoxia cristiana de los siglos XV y XVI pueden rastrearse tanto en los códices, los tratados, los libros de catecismo, las obras doctrinales y los sermonarios.

Se constituye -a la vez que se construye- a través de estos mecanismos un campo religioso claro y específico, donde están presentes la transacción y el interés de las diferentes clases en juego. Las diversas estrategias de los agentes involucrados pueden analizarse tanto en la acción desarrollada por los monjes como por la Iglesia, tendientes a lograr un habitus catholicus, como en la pervivencia de tradiciones propias de la religiosidad popular, expresadas en cultos locales, santos patronos, procesiones de Semana Santa, entre otros.

El resultado de estas múltiples relaciones evidencia la posición que cada clase ocupa en el campo, dando como resultado una determinada estructuración social entre dominantes y dominados.

El capital religioso, resultado del monopolio de gestión, está destinado a modificar el habitus de los laicos. De allí la importancia de la "verdadera y sagrada docthrina catholica". Sin duda, los textos guadalupanos constituyen una parte substancial de este capital, dado que están asociados a la difusión de la ideología de las clases dominantes, esto es, de la jerarquía católica y la monarquía castellana.

Esta imposición es el resultado de la relación dialéctica entre la fuerza material y simbólica de los grupos o clases que pueden monopolizar bienes y servicios capaces de satisfacer intereses religiosos, la naturaleza de estos bienes y servicios, la 
mediación de la posición en la instancia productora del campo religioso y el capital de la autoridad religiosa.

Esta relación dialéctica se halla regulada por los principios de armonía -entre oferta religiosa y demanda laica- y de homología -entre las posiciones en el campo y en la estructura de clases-.

Sin duda, esta perspectiva analítica brinda herramientas conceptuales para interpretar los textos seleccionados y superar, en parte, las dificultades y limitaciones que plantea recurrir a este tipo de obras -en particular los milagros- como fuente histórica.

En este plano de la plasmación escrita del acontecimiento se observa lo que $P$. Bourdieu denomina la burocratización y sistematización llevada a cabo por el sector dominante del campo religioso, que posee la mayor cantidad de capital simbólico como para operar en tal sentido.

Un ejemplo, a partir de los textos guadalupanos. En el Nuevo Testamento ocupa un lugar de importancia el aprendizaje de textos bíblicos por parte de Jesús. A través de este recurso se pone de manifiesto la actitud y aptitud del Mesías -desde pequeño- en cuanto a la interpretación de la Verdad, a pesar de encontrarse en un ámbito intelectual judío por excelencia, el Templo $^{36}$ y en la ciudad santa, Jerusalén. Esta ciudad ocupa, de san Marcos a san Juan, un puesto cada vez mayor en los Evangelios, pero es en san Lucas donde mejor se expone su papel, dado que es el centro de todo el drama sagrado: en la vida de Jesús es Jerusalén el lugar donde todo desemboca y es en ella donde comienza la historia del testimonio apostólico ${ }^{37}$.

Es por ello que considero que el peregrinaje de Alí a Jerusalén en búsqueda de la Verdad previa a la conversión y el bautismo debe leerse en clase simbólica. De esta manera, Alí sigue los pasos del Salvador, convirtiéndose en un nuevo Jesús a partir de su imitación ${ }^{38}$.

En síntesis, los ejemplos tomados de las diversas prácticas religiosas propias de Europa entre en los siglos I y XVI se encuentran definidas y conformadas a partir de determinados 
discursos, que buscan estructurar un horizonte de vida cristiano, de acuerdo a las pautas de cada época.

Discursos y pautas monopolizadas por apóstoles, por diversas órdenes religiosas, por la Iglesia, por la Inquisición que con sus "dichos y hechos", sus acciones, sus palabras y sus ejemplos conforman y determinan la ortodoxia en un campo religioso que, por momentos, aparece lábil, con contornos difusos pero que se caracteriza, según Alain Boureau, por la "eficacia del discurso" ${ }^{39}$.

RODRÍGUEZ, Gerardo. "Migration" and "Immigration" in religion: the religious diversity in Middle Ages. História, v.27, n.2, p. 177-201, 2008.

Abstract: Migration and immigration, as such as religious diversity are expressions that bring back irregular and conflictive cultural contacts. It's about men and women of Antiquity and Middle Ages in a dialectical and constant game of acceptation and denial, assimilation and xenophobia. It's also about the relationship between people with different behaviors, ideology, and religion.Those different people are feared due to many reasons. They are the "others", of whom we don't know all characteristics, and who (maybe) will modify the receptor's characteristics. That identity has spaces and boundaries, spaces and frontiers. They are physical and cultural spaces, real or imaginary spaces, that denial or accept us. Limited spaces and multiple boundaries, all them bring back cultural contacts and frontiers.

Keywords: Migration; Cultural contacts; Identity.

\section{NOTAS}

${ }^{1}$ Conferencia de apertura. III Ciclo de Estudos Antigos e Medievais "Migrações e Imigrações em Religiões na Antiguidade e Medievalidade" UNESP - Assis - Brasil. Assis, 13 y 14 de mayo de 2008. 
2 Emilio MITRE FERNÁNDEZ, "La cristiandad medieval y las formulaciones fronterizas", en: AA.VV., Fronteras y fronterizos en la historia, Valladolid, 1997, pp.7-62. Este autor plantea un esquema a tener en cuenta en las investigaciones sobre el hecho fronterizo en el Occidente medieval, basado en las formulaciones, las percepciones y las concreciones o creaciones fronterizas -cf. Apéndice I, pp.55-57-. Esta importancia queda atestiguada en los Congresos que sobre diversos aspectos de la vida fronteriza organiza cada dos años, desde 1995, el Ayuntamiento de Alcalá la Real. Cf. Carlos de AYALA MARTÍNEZ, Pierre BURESI y Philippe JOSSERAND (Eds.), Identidad y representación de la frontera en la España medieval (Siglos XI-XIV), Madrid, 2001 y Rui M. LOUREIRO y Serge GRUZINSKI (Dirs.), Passar as Fronteiras. Actos do II Coloquio Internacional sobre Mediadores Culturais. Seculos XV a XVIII, Lagos, 1999. Esta última obra recoge veintiún ponencias que se agrupan en cuatro grandes bloques, los cuales me interese señalar: los mediadores culturales -entre los que se mencionan a los traficantes de esclavos, cautivos, monjes y comerciantes-, el mestizaje biológico y cultural, las resistencias al mestizaje y las fronteras -externas, internas-.

${ }^{3}$ Con relación a esta mistificación cf. Bart EHRMAN, Simón Pedro, Pablo de Tarso y María Magdalena. Historia y leyenda del cristianismo primitivo, Barcelona, 2006.

${ }^{4}$ Gerard LUTTIKHUIZEN, La pluriformidad del Cristianismo Primitivo, Córdoba, 2002.

${ }^{5}$ Cf. Bart EHRMAN, Cristianismos perdidos. Los credos proscriptos del Nuevo Testamento, Barcelona, 2004.

6 Francisco GARCÍA BAZÁN, "Sobre los orígenes de la filosofía cristiana y su proyección en la cultura actual", en: Jorge ESTRELLA, Gerardo RODRÍGUEZ, María Luján DÍAZ DUCKWEN (eds.), Del cristianismo antiguo al cristianismo medieval, Mar del Plata, 2007, pp.317-328.

${ }^{7}$ Eric HOBSBAWM, "Introducción: la invención de la tradición", en: Eric HOBSBAWM y Terence RANGER (eds.), La invención de la tradición, Barcelona, 2002 (1 1 $^{\text {a }}$ edición en inglés 1983), pp.7-21. Cf. Gerd ALTHOFF, Johannes FRIED and Patrick GEARY (eds.), Medieval Concepts of the Past. Ritual, Memory, Historiography, Washington D.C. and Cambridge, 2002; Alfred SMYTH (ed.), Medieval Europeans. Studies in Ethnic Identity and National Perspectives in Medieval Europe, London, 1998. 
${ }^{8}$ ERNOLD LE NOIR, Poème sur Louis Le Pieux, et Épîtres au Roi Pépin, édités et traduites par Edmond Faral, París, 1964, $2^{\mathrm{a}}$ edición (1 ${ }^{\mathrm{a}}$ edición 1932). Sobre Ermoldo vid. Philippe DEPREAUX, "Poétes et historiens au temps de l'empereur Louis le Pieux", en: Le Moyen Age 99, Bruselas, 1993, pp.311-332 y Mauro DONNINI, "L'ars narrandi nel Carmen in honorem Hludowici di Ermoldo Nigello", en: Studi Medievali 47-1, $3^{\mathrm{a}}$ serie, Spoleto, 2006, pp.111-176.

${ }^{9}$ Karl WERNER, "Hludovicus Augustus. Gouverner l'empire chrétien Idées et réalités", en: Peter GODMAN and Roger COLLINS (eds.), Charlemagne's Heir. New Perspectives on the Reign of Louis the Pious (814-840), Oxford, 1990, p.116, p.118.

${ }^{10}$ Cf. Peter GODMAN, Poets and Emperors. Frankish Politics and Carolingian Poetry, Oxford, 1987; Walter GOFFART, The Narrators of Barbarian History (A.D. 550-800). Jordanes, Gregory of Tours, Bede, and Paul the Deacon, Indiana, 2005, $2^{\text {a }}$ edición (1 $1^{\text {a }}$ edición 1988); Rosamond MCKITTERICK (ed.), Carolingian Culture: emulation and innovation, Cambridge, 1994; Rosamond MCKITTERICK, History and Memory in the Carolingian World, Cambridge, 2004.

${ }^{11}$ Cf. Daniel RUSSO, "Les représentations mariales dans l'art d'Occident du Moyen Âge. Essai sur la formation d'une tradition iconographique", en: Dominique IOGNA-PRAT, Éric PALAZZO, Daniel RUSSO (eds.), Marie. Le culte de la Vierge dans la société médiévale, Préface de Georges Duby, París, 1996, pp.218-19; Éric PALAZZO, "Marie et l'élaboration d'un espace ecclésial au haut Moyen Âge", en: D. IOGNAPRAT, E. PALAZZO, D. RUSSO , Marie..., p.321.

${ }^{12}$ En esta Iglesia, incendiada en 873, Ermoldo pasó su encierro/exilio, lo que demuestra su condición de hombre de la Iglesia. Cf. Edmond FARAL, "Introduction", en: ERNOLD LE NOIR, Poème..., p.VI.

13 Los v.2531-32 expresan "Virgo Maria, tibi quo templa dicata nitescunt, / Quo tuus in terris rite veretur honos".

${ }^{14}$ Este canto del gallo anuncia el tiempo medio entre la medianoche y la aurora. Cf. $M C$ 13, 35; 14, 30.68.72.

${ }^{15}$ Los v.2578-79 se refieren a esta aparición en los siguientes términos "Lumine perfusos, vestitos vestibus albis, / Candidiora nive corpora, lacte caput". Es preciso recordar que la nieve designa la pureza y, sobre todo, la blancura (Ex 4, 6; Sal 50, 9; Is 1, 18; Dan 7, 9; Mt 17, 21; $28,3)$ en tanto la leche, en sentido figurado, puede interpretarse como los elementos de la doctrina cristiana (1 Cor 3,2; Heb 5, 12-13; 1 Pe 2, 2). ${ }^{16}$ Cf. Sylvie BARNAY, El Cielo en la Tierra. Las apariciones de la Virgen en la Edad Media, Prólogo de Jean Delumeau, Madrid, 1999; Antonio 
ROYO MARÍN, La Virgen María. Teología y espiritualidad marianas, Madrid, 1997, $2^{\mathrm{a}}$ edición corregida y aumentada ( $1^{\mathrm{a}}$ edición en español 1996).

17 Esta luminosidad interpretada como protección divina tiene fuerte raigambre neotestamentaria. Cf. Act 12, 1-11; 16, 25-27.

${ }^{18}$ Ex 19, 4; Dt 32, 11.

${ }^{19}$ En especial 2 Cor 12, 1-7.

${ }^{20}$ Louis CHARBONNEAU-LASSAY, El Bestiario de Cristo. El simbolismo animal en la Antigüedad y la Edad Media, 2 volúmenes, Palma de Mallorca, 1997, vol.2, p.662.

21 Guy PHILIPPART, "Le récit miraculaire marial dans l'Occident médiéval", en: D. IOGNA-PRAT, É. PALAZZO, D. RUSSO, Marie..., pp.566-67 afirma que los milagros mariales son raros durante el primer milenio debido al auge de la acción milagrosa de los santos del cielo, lo que podría deberse, en parte, a la ausencia de reliquias de la Virgen.

${ }^{22}$ Dominique IOGNA-PRAT, "La Vierge et les ordines de couronnement des reines au IX siècle", en: D. IOGNA-PRAT, É. PALAZZO, D. RUSSO, Marie..., p.101; É. PALAZZO, "Marie et l'élaboration d'un espace ecclésial au haut Moyen Âge", en: D. IOGNA-PRAT, É. PALAZZO, D. RUSSO , Marie..., pp.314-317.

${ }^{23}$ Nilda Guglielmi a desarrollado estos tópicos en varias de sus ediciones críticas. Cf. Odorico da PORDENONE, Relación de viaje, prologo, traducción y notas de Nilda GUGLIELMI, Buenos Aires, 1987; Jacques de VITRY, Historia de las Cruzadas, prólogo, traducción y notas de Nilda GUGLIELMI, Buenos Aires, 1991; Nilda GUGLIELMI, Guía para viajeros medievales (Oriente, siglos XIII-XV), Buenos Aires, 1994.

${ }^{24}$ Floreal FORNI, "Reflexión sociológica sobre el tema de la religiosidad popular", en: Sociedad y Religión, 3, 1986, p.5.

${ }^{25}$ Archivo Monasterio de Guadalupe, Los Milagros de Guadalupe, el C1 recoge el primer milagro fechado en 1407, en tanto el C9 recoge milagros correspondientes a los años 1704 a 1722. Los cinco primeros códigos son de pergamino (el $\mathrm{C} 4$ tiene algunos folios de papel), en tanto que los códices 6 y 7 están escritos parte en pergamino, parte en papel y los dos últimos enteramente en papel.

${ }^{26}$ Ugolino VERINO, De expugnatione Granatae, Introducción, Edición y Traducción de Inmaculada LÓPEZ CALAHORRO, Granada, 2002.

${ }^{27}$ Jerónimo (de la Madre de Dios) GRACIÁN DANTISCO, Tratado de la redención de cautivos, edición y prólogo de Miguel Ángel de BUNES IBARRA y Beatriz ALONSO ACERO, Madrid, 2006. 
${ }^{28}$ Pierre BOURDIEU, Esquisse d'une théorie de la pratique, précédé de trois études d'ethnologie kabyle, París, 1972, p.31.

${ }^{29}$ GRACIÁN, p.38. Cf. Mercedes GARCÍA ARENAL y Miguel Ángel de BUNES IBARRA, Los españoles y el norte de África, siglos XV-XVIII, Madrid, 1992, p.212 afirman que Argel llegó a contar con 25.000 cautivos hacia mediados del siglo XVI. José MARTÍNEZ TORRES, Prisionero de los infieles. Vida y rescate de los cautivos cristianos en la Mediterráneo musulmán (silgos XVI-XVII), Barcelona, 2004, p.23 considera que la quinta parte de los habitantes de Argel a principios del siglo XVII estaba compuesta de cautivos españoles, lo que da cuenta de las dimensiones humanas y sociales del cautiverio. Otros autores estiman que el número fue mucho menor, no así su importancia, relacionada directamente con el tema de los renegados y la actuación de la Inquisición. Esta tesis ha sido recientemente defendida por Jarbel RODRÍGUEZ, Captives and Their Saviors in the Medieval Crown of Aragon, Washington D.C., 2007.

${ }^{30}$ Silvano SANTIAGO, "El entrelugar del discurso latinoamericano", en: Adriana AMANTE y Florencia GARRAMUÑO (Comps.), Absurdo Brasil. Polémicas en la cultura brasileña, Buenos Aires, 2001, p.65. Estas tensiones representan las luchas entre dominates y dominados que son propias de un campo, en la terminología de P. Bourdieu, en particular el campo religioso. Al respecto vid. Pierre BOURDIEU, "Genèse et structure du champ religieux", en: Revue française de Sociologie NoXII, París, 1971, pp.295-334.

${ }^{31}$ Manuel SÁNCHEZ, "La represión de la disidencia ideológica en el discurso religioso medieval", en: Ángel VACA LORENZO (ed.), Disidentes, heterodoxos y marginados en la historia, Salamanca, 1998, p.85.

${ }^{32}$ Grado MERLO, "Coertion et orthodoxie: modalités de communication et d'imposition d'un message religieux hégémonique", en: AA.VV., Faire croire. Modalités de la diffusion et de la réception des messages religieux du XIIe au XVe siècle. Table ronde organisée par l'École française de Rome, en collaboration avec l'Institut d'histoire médiévale de l'Université de Padoue (Rome, 22-23 juin 1979), Roma, 1981, pp.101118.

${ }^{33}$ Francisco FERNÁNDEZ CONDE, La Religiosidad Medieval en España. 1: Alta Edad Media (S. VII-X), Oviedo, 2000, pp.530-531.

${ }^{34}$ Cf. Pierre BOURDIEU, El sentido práctico, Madrid, 1991, p.92 (tomado y adaptado de la noción de habitus). 
${ }^{35}$ Pedro CÁTEDRA, Liturgia, poesía y teatro en la Edad Media. Estudios sobre prácticas culturales y literarias, Madrid, 2005, p.14. El intérprete es fundamental, dado que actúan de nexo entre los textos normativos y la comunidad, que puede ser iletrada.

${ }^{36} L C 2,40-52$.

${ }^{37}$ Michel JOIN-LAMBERT y Pierre GRELOT, "Jerusalén", en: Xavier LEÓN-DUFOUR (dir.), Vocabulario de Teología Bíblica, Barcelona, 1996, $17^{\mathrm{a}}$ edición revisada y ampliada, pp.434-439.

38 AMG, LMG, C1, fo142 vto. Es interesante notar que estando en Jerusalén Alí se encuentra con un monje negro etíope que lo pone al tanto de la existencia del reino del Preste Juan. Sin duda, esta referencia a una leyenda extendida y popular no hace más que reforzar la importancia de esta peregrinatio.

39 Alain BOUREAU, L'événement sans fin. Récit et christianisme au Moyen Âge, País, 1993.

Artigo recebido em 08/2008. Aprovado em 10/2008. 


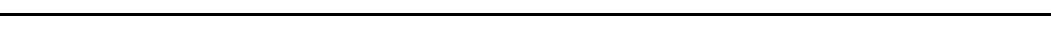

